\title{
METODOLOGIA DE PESQUISA NO SISTEMA PRISIONAL E AS CONTRIBUIÇÕES DE FORA E DE DENTRO DAS GRADES: A PESQUISA TRADICIONAL E A CARTOGRAFIA DO SUJEITO INTERNO-PESQUISADOR
}

\author{
André Yan César Silvério ${ }^{1}$ \\ Camila Caldeira Nunes Dias ${ }^{2}$
}

\begin{abstract}
Resumo
O presente trabalho coloca em perspectiva as metodologias utilizadas na pesquisa em instituições prisionais a partir de duas posições relacionais: a posição externa, que se estabelece a partir de uma separação entre o pesquisador e a prisão, demarcada pelo processo de entradas e saídas no território do trabalho de campo, e a posição interna, que se estabelece por meio da experiência e da vivência involuntária do sujeito na instituição prisional. Apresentamos as respectivas estratégias de pesquisa, os desafios e dificuldades enfrentadas, e as possibilidades de ação no contexto de cada uma destas perspectivas a fim de propiciar uma reflexão metodológica sobre a realização de pesquisas em instituições prisionais. Devido à menor produção acadêmica relativa especificamente à posição interna aqui proposta, desenvolvemos estas possibilidades investigativas com maior escopo neste texto, procurando para tanto articular ferramentas e estratégias da autoetnografia e da cartografia.
\end{abstract}

Palavras-chave: Prisão. Metodologia. Subjetividade. Autoetnografia. Cartografia.

\begin{abstract}
:
The present work puts in perspective the methodologies used in research in prisons from two relational positions: the external position, which is established from a separation between the researcher and the prison, delimited by the process of entering and leaving the territory, and the internal position, which is set through the subject's involuntary experience inside the prison. We present the research strategies, the challenges and difficulties faced, and the possibilities for action in the context of each of these positions, in order to provide a methodological reflection over research in prisons. Due to the lack of specific academic papers for the internal position proposed here, we developed these investigative possibilities with greater scope in this article, aiming to articulate research tools and strategies from autoetnography and cartography.
\end{abstract}

Keywords: Prison. Methodology. Subjectivity. Autoetnography. Cartography.

\footnotetext{
${ }^{1}$ Metrando em Ciências Humanas e Sociais pela UFABC - Universidade Federal do ABC. Psicólogo e Bacharel em Psicologia pela Universidade Estadual Paulista (Unesp-Assis). Integrante do Grupo de Pesquisa em Segurança, Violência e Justiça (SEVIJU) da UFABC. E-mail: yan.silverio@gmail.com.

${ }^{2}$ Doutora e Mestre em Sociologia pela USP - Universidade de São Paulo; Professora Adjunta da UFABC - Universidade Federal do ABC. Coordenadora do Grupo de Pesquisa em Segurança, Violência e Justiça (SEVIJU) da UFABC. Pesquisadora colaboradora do Núcleo de Estudos da Violência (NEV) da Universidade de São Paulo. E-mail: camila.dias@ufabc.edu.br.
} 


\section{Introdução}

O sistema prisional brasileiro, entendido aqui como as instituições e os atores que o compõe, é historicamente um campo de amplos conflitos éticos e políticos (MISSE, M, 2006; ADORNO, S. 1996). Com a terceira maior população carcerária do planeta (BRASIL, 2019), o Brasil coleciona histórias de brutalidade, abandono e toda sorte de violência física e simbólica conforme pode ser atestado por um acúmulo de denúncias de diversas entidades e de trabalhos acadêmicos que foram realizados na última década (RELATÓRIO HUMAN RIGHTS WATCH, 2020; INFORME ANISTIA INTERNACIONAL, 2021; RELATÓRIO DE DIREITOS HUMANOS DO NÚCLEO DE ESTUDOS DA VIOLÊNCIA, 2020; DIAS, 2017) ${ }^{3}$.

Deste modo a prisão vem historicamente se constituindo reiteradamente no Brasil como espaços de imposição de várias formas de opressão e de sofrimento aos seres humanos, ponto de origem e de articulação de organizações criminosas (DIAS, 2013), celeiro de sentimentos de revolta e de percepções de injustiça. Os servidores que ali estão a serviço do Estado certamente vivenciam alguns dos problemas vivenciados pelos presos, sofrendo o processo social que já foi amplamente analisado e denominado "prisionização" (CLEMMER, 1958; THOMPSOM,[1976]2002) e as diferentes formas de discriminação e estigmatização social em relação à instituição prisional e à todos que nela circulam (MARQUES, GIONGO; RUCKERT, 2018). Suas práticas institucionais quase que se limitam à busca de controle e segurança, através da imposição de uma multiplicidade de práticas punitivas que abrange comportamentos os mais variados e, em geral, não tem relação com os princípios normativos da funcionalidade da prisão previstos no ordenamento jurídico (COELHO [1987]2005; DIAS, 2014).

As dinâmicas institucionais próprias do espaço prisional acabam por intensificar a importância da prisão na conformação de uma identidade delinquente (RAMALHO [1976] (2002); FOUCAULT, [1975]2007) reiterando processos políticos, sociais e históricos que demarcam determinados segmentos da população como alvos do aparato do sistema de justiça criminal, funcionando na forma de uma "porta giratória", em que quanto mais os indivíduos nela permanecem, maiores são as possibilidades de que eles continuem presos - simbólica e literalmente - nas malhas desse sistema perverso e excludente.

Michel Foucault ([1975]2007) ainda no século passado, já apontava como a instituição prisional atua de maneira a manter as condições que renovam a necessidade da sua existência e que impelem à demanda política de ampliação da sua capacidade física e de sua centralidade como mecanismo de controle social. O processo de renovação da importância da prisão passa, essencialmente, pelo apontamento de suas falhas em reiterados diagnósticos a partir dos quais as propostas de reformas garantem que a prisão permaneça sendo o remédio para o seu próprio fracasso, conformando desta forma a sua função política.

No Brasil, estudos clássicos sobre as instituições prisionais foram fortemente inspirados nas perspectivas de Foucault (Ramalho, [1976] 2002) e nos estudos norte-americanos, notadamente nos clássicos Donald Clemmer (1958) e Gresham Sykes (1974) - como é o caso de August Thompson ([1976] 2002) e Edmundo Campos Coelho ([1987] 2005). A atualização da análise foucaultiana para

\footnotetext{
${ }^{3} \mathrm{O}$ Mecanismo Nacional de Proteção e Combate à Tortura, a despeito do desmonte que vem sofrendo desde o início do Governo de Jair Bolsonaro, apresenta uma importante radiografia das violações de direitos nas prisões em todo o país. Ver: https://mnpctbrasil.wordpress.com/relatorios/
} 
o contexto brasileiro e, mais especificamente no caso de Ramalho, para a análise da Casa de Detenção de São Paulo, situando a centralidade da função política da prisão no mundo moderno justamente naquilo que o discurso oficial apresenta como o seu fracasso e ponto em torno do qual circulam as narrativas da reforma mostrava-se bastante profícua para a compreensão das mazelas das instituições brasileiras.

Outra chave teórico-analítica que apresentou elementos conceituais bastante recorrentes nos trabalhos sobre as prisões brasileiras no campo das ciências sociais pode ser localizada na perspectiva de Sykes (1974), segundo a qual a prisão apresentava uma falha estrutural na pretensão de exercer poder total sobre os presos e, em decorrência disso, a dinâmica prisional é centrada em torno de acomodações entre administração prisional e população carcerária, o que inclui a transferência de poder para os presos e a conformação de um sistema fragilmente equilibrado em torno destas relações ao mesmo tempo de cooperação e de desconfiança. Um sistema social baseado num frágil equilíbrio e cuja ruptura da ordem - expressa através de movimentos coletivos como rebeliões e motins - parece ser algo sempre eminente. Essa vertente analítica foi importante, por exemplo, na análise que Coelho ([1987]2005) propôs sobre o impacto da transição política da década de 80 no sistema prisional do Rio de Janeiro, provocando desestabilização, desordem e violência em razão de mudanças bruscas que solaparam as bases de sustentação do frágil equilíbrio que garantia a ordem nas prisões fluminenses.

A partir dos anos 90 percebe-se um aumento significativo dos trabalhos brasileiros sobre o sistema prisional dentro do campo das ciências sociais. Um aumento da quantidade de pesquisa e uma ampliação dos temas, das perspectivas teóricas e metodológicas propostas para compreender esse universo (LOURENÇO; ALVAREZ, 2018). Neste mesmo período, assistiu-se à ampliação da população carcerária e das instituições carcerárias com a adoção da política de encarceramento em massa que começa a tomar forma no Brasil nesta década e que irá produzir um universo novo, fenômenos que emergiram justamente a partir dos muros prisionais.

Contudo, a despeito do incremento do campo de estudos prisionais no âmbito das ciências sociais, são poucas as propostas de reflexões propriamente metodológicas sobre a pesquisa em instituições fechadas, tais como a prisão (DIAS, 2010; DIAS, ROCCA; CONCEIÇÃO, 2015; DIAS, 2012). Situar os desafios, os impedimentos e as possibilidades de construir conhecimento sobre dinâmicas em instituições fechadas, bem como de acessar alguns lampejos das vivências e experiências que ocorrem nestes espaços e a partir dos quais se torna possível construir a reflexão crítica e problematizar o lugar da prisão na sociedade contemporânea, é tarefa fundamental para o avanço teórico e metodológico de um campo de estudos em crescimento e que assume maior centralidade no debate acadêmico, social e político. Neste sentido, este trabalho pretende contribuir com uma das lacunas existentes no campo dos estudos prisionais e propor uma reflexão crítica sobre o conhecimento produzido sobre o universo prisional a partir de perspectivas metodológicas caracterizadas por diferentes formas de acesso à instituição prisional. Chamaremos aqui de perspectiva "externa" a estratégica metodológica tradicional no campo das ciências sociais e que consiste no acesso à instituição prisional por um sujeito que é exterior a esse universo; e de perspectiva "interna", a estratégia metodológica em que o conhecimento é produzido a partir do próprio sujeito aprisionado no lado de dentro das grades.

A perspectiva metodológica externa trata da pesquisa feita em um contexto onde pesquisador e instituição se articulam em termos do objetivo específico daquele trabalho e onde as situações de contato entre os sujeitos são definidas a partir de um tempo e espaço demarcados pelo processo de pesquisa e do acesso do pesquisador - as entradas e as saídas - ao território do trabalho de campo 
(DIAS, 2012, 2015). Em geral, o tempo e o espaço da pesquisa, neste caso, são constituídos através de acordos e negociações prévias entre o pesquisador e a administração prisional através de procedimentos formais e burocráticos que demarcam certos limites ao trabalho do pesquisador na instituição. Uma vez que consiga adentrar o espaço do cárcere, é através de uma série de relações estabelecidas pelo pesquisador com os sujeitos que circulam nesses estabelecimentos, especialmente os servidores e os presos, que vão se delineando de maneira mais concreta os contornos da pesquisa, alargando ou restringindo o campo definindo burocraticamente, mas, mantendo a posição do pesquisador marcada pela sua exterioridade ao cárcere, posição essa que permeia as dinâmicas e as relações estabelecidas neste contexto.

A perspectiva metodológica interna se refere à pesquisa realizada por um pesquisador institucionalizado, durante a própria vivência do cotidiano do cárcere, das experiências e do conhecimento involuntariamente aprendido acerca dos processos, das dinâmicas e dos atores daquele universo institucional em uma literal imersão no campo na condição de privação de liberdade. Nessa condição outras ferramentas metodológicas menos exploradas pela literatura se fazem possíveis e são apresentadas na terceira parte deste texto, que tem como proposição a composição de um exercício cartográfico do território prisional a partir de seus elementos de controle e das relações interpessoais estabelecidas no interior das instituições. A partir desta vivência na prisão, é possível encontrar força em uma proposta de análise sócio-afetivo-cultural das relações possíveis entre os indivíduos que compõem os diferentes grupos do ambiente prisional para fundamentar a criação de uma cartografia do cárcere a partir do método autoetnográfico como base e ponto de partida.

\section{Por um saber sobre as prisões}

Chies (2015) sugere que a "Questão penitenciária" brasileira possa ser construída como Campo sui generis na acepção de Pierre Bourdieu e em termos de constituição de um Campo, nos termos de Georgio Agambem. Para o autor, situar a questão penitenciária como campo nestas duas acepções teóricas, permitiria a formação de grades-teóricos instrumentais potentes, superando obstáculos epistemológicos e subterfúgios retóricos e políticos que muitas vezes estão associados à questão penitenciária. Assim, reconhecer a questão penitenciária nos termos de Agambem (que aqui nos interessam mais especificamente) é sugerir que "se reconheça que o ato de encarcerar um indivíduo nos ambientes prisionais nacionais significa sua entrega e manutenção numa esfera de indeterminação entre o dentro e fora da lei, no qual existe uma gestão biopolítica do 'deixar sofrer, deixar morrer"'. (CHIES, 2015, p. 84).

Consideramos que a reflexão metodológica elaborada através de cartografias construídas a partir da autoetnografia do pesquisador posicionado nesta zona de indeterminação interna pode estabelecer um diálogo epistemológico com a proposta teórica apresentada em Chies (2015) e, neste sentido, contribuir para a potencialização de uma grade teórica e, sobretudo, metodológica que situe a questão penitenciária como Campo na acepção de Agambem.

Quando Chies (2015) sugere o reconhecimento da questão penitenciária brasileira na chave do conceito de Campo, de Agambem, ele argumenta que o risco em não reconhecer a possibilidade concreta de inserir a prisão na grade teórica interpretativa do estado de exceção, no qual se situa esse conceito de Campo, poderia representar uma armadilha para a naturalização das gramáticas e violência, de segregação e de morte, desviando o foco do enfrentamento dos elementos macroestruturais "que, produzindo e mantendo o Campo, o eufemizam como Crise" (CHIES, 2015, p. 88). Ainda na argumentação do autor, a adoção da grade teórica proposta permite ultrapassar "os níveis superficiais dos 'horrores e dilemas da execução penal' e adentrar, através de seus meandros, 
na densidade estrutural e operacional do Campo Penitenciário [...]” (CHIES, 2015, p. 88). Este texto pretende justamente contribuir com algumas reflexões metodológicas e, quiçá, algumas provocações de ordem epistemológica acerca dos meandros da dinâmica prisional, das filigranas das relações sociais que se estabelecem nestes espaços e estruturam processos internos de controles sociais, formais e informais (DIAS; SALLA, 2017; 2019).

Conforme pontuado anteriormente, as dificuldades de produção de conhecimento científico no ambiente prisional são permeadas por facetas burocráticas e relacionais desafiadoras que contribuem para o ocultamento das dinâmicas prisionais e suas problematizações urgentes.

Wacquant (2002) aponta que a expansão do encarceramento nos Estados Unidos foi acompanhada da simultânea redução das etnografias realizadas no espaço prisional e do acesso de pesquisadores a essas instituições. Deste modo, a opacidade das prisões aumenta na mesma proporção em que cresce o número de pessoas encarceradas e o tamanho da rede penitenciária nos Estados Unidos.

Nos últimos anos, em vários estados brasileiros, mas, sobretudo, em São Paulo, ocorreu um processo de recrudescimento das condições para autorização de pesquisa no espaço prisional. A instituição de instâncias decisórias e de controle no âmbito da administração prisional logrou produzir obstáculos que dificultaram o acesso aos cárceres para os pesquisadores, ampliando e prolongando expedientes burocráticos que, na realidade, acabaram por impossibilitar uma boa parte das pesquisas.

Algumas estratégias passaram a ser utilizadas para 'driblar' essa impossibilidade de acesso, por exemplo, a realização de pesquisas através de entrevistas com servidores ou ex-servidores e/ou com egressos/as prisionais. Adentrar as instituições prisionais através da participação em entidades que possuem prerrogativas de acessar as prisões para fiscalização das condições encarceramento, tais como Pastoral Carcerária, Conselho da Comunidade, Mecanismo Nacional de Prevenção Contra a Tortura tem sido outra estratégia utilizada (GODOI, 2019; BRITO, 2017). De forma planejada ou não, o acesso através dessas entidades passou a se constituir como atalho para adentrar o universo prisional num contexto de intensas restrições de controles estritos sobre as informações acerca do universo dos cárceres.

Há um conjunto de trabalhos sobre as questões carcerárias realizados a partir de dados mais abrangentes (INFOPEN ${ }^{4}$ ou outros dados quantitativos) que colocam a questão prisional no panorama político, econômico ou social brasileiro (ver, por exemplo, SINHORETTO, 2015). Ainda, tem-se várias pesquisas que se constroem a partir de fontes secundárias e se debruçam sobre documentos da imprensa, processos judiciais, inquéritos policiais, relatórios de entidades privadas ou estatais diversas. Indiscutivelmente, trata-se de um campo fértil e importante, considerando-se ainda a centralidade cada vez maior das articulações entre as dinâmicas prisionais a as dinâmicas externas às instituição (GODOI, 2010) e que nos leva a atualizar a acepção clássica da separação irrestrita entre prisão e sociedade, tal como pressuposto, por exemplo, no conceito de instituição total de Goffman (ADORNO; DIAS,, 2017; GOFFMAN, 1987).

No entanto, apesar da importância da análise e da reflexão que esse conjunto de trabalhos oferece à compreensão da prisão em seus diversos aspectos, essencialmente, nos mecanismos formais de controle, punição e segregação que tomam forma na sociedade brasileira atual, o conhecimento sobre as dinâmicas internas às prisões, das relações de poder e de solidariedade, cooperação, disputa ou conflitos, entre presos e funcionários ou entre presos e entre funcionários; as violências e as violações; as punições e castigos internos, oficiais e não oficiais; os sofrimentos, as dores, as carências, as formas de resistência e de existência são dimensões fundamentais que acabam por demandando a

\footnotetext{
${ }^{4} \mathrm{http}$ ://dados.mj.gov.br/dataset/infopen-levantamento-nacional-de-informacoes-penitenciarias
} 
inserção do pesquisador no espaço prisional e não pode ser substituída por outras estratégias de pesquisa - ao menos, não no mesmo sentido, da mesma forma e com o mesmo conteúdo em termos do conhecimento produzido. E é neste sentido da pesquisa sobre prisões e, sobretudo, em prisões, que esse texto pretende colaborar a partir de uma discussão metodológica que parte das formas de acesso do pesquisador ao universo interno da instituição prisional e do conhecimento que é possível produzir a partir das posições específicas definidas ao longo destes caminhos de acesso.

Para tanto, coloca em perspectiva as metodologias utilizadas na pesquisa em instituições prisionais a partir de duas posições relacionais: uma que se estabelece de fora para dentro, a partir de uma exterioridade prévia entre o pesquisador e o universo prisional; outra, que se estabelece através da experiência interna e da condição involuntária de pesquisador encarcerado e, portanto, submerso na vivência dentro da instituição prisional.

Em primeiro lugar, teceremos algumas breve reflexões sobre a perspectiva externa, considerada como a pesquisa feita em um contexto onde pesquisador e instituição se articulam em termos do objetivo específico daquele trabalho e onde as situações de contato entre os sujeitos são definidas a partir de um tempo e espaço demarcados pelo processo de pesquisa e do acesso do pesquisador - as entradas e as saídas - ao território do trabalho de campo. Em geral, o tempo e o espaço da pesquisa, neste caso, são constituídos através de acordos e negociações prévias entre o pesquisador e a administração prisional e através de uma série de relações internas do pesquisador com os sujeitos da pesquisa. A despeito de não ser abundante, há alguns trabalhos já publicados que se referem ou tangenciam essa perspectiva metodológica, razão pela qual ela será apresentada de forma mais sintética e sem reproduzir o que já foi escrito à respeito.

A perspectiva interna está referida como a pesquisa feita por um pesquisador institucionalizado, durante a sua própria vivência do cotidiano do cárcere, das experiências e do conhecimento involuntário acerca das dinâmicas e dos atores daquele universo institucional, em uma literal imersão no campo na condição de privação de liberdade. Por inúmeros motivos, dentre eles os desafios de acesso dos sujeitos encarcerados à formação escolar/acadêmica e, portanto, das barreiras sociais e institucionais que emergem e dificultam a produção desse conhecimento, assim como dos contornos próprios do campo acadêmico em suas estruturas formais de reconhecimento e de legitimação do conhecimento produzido enquanto conhecimento cientificamente válido, trata-se de uma reflexão praticamente inexistente no campo de estudos prisionais brasileiro. Dessa forma, para melhor explorar as potencialidades e a potência dessa reflexão, ela terá um escopo maior neste texto.

Neste caso, o arcabouço metodológico se apresenta como síntese do sentido ético-interventivo da pesquisa de campo. O método com o qual o pesquisador executa suas práticas investigativas determina não apenas os resultados finais da pesquisa, mas principalmente o alcance de seu potencial em investigar. Considerando as condições epistemológicas das ciências sociais é prudente se distanciar da noção do encontro de resultados definitivos, mas antes, considerar que o que se busca é o registro de processos e dinâmicas altamente mutáveis e que, portanto, nos fornecem, no máximo, pistas e indicativos diagnósticos em determinados tempos e espaços.

Sabe-se que os meios de pesquisa determinarão sobremaneira o resultado final destas incursões. Ademais, o método por si só não garante uma prática incisiva, assim como uma prática vigorosa e entusiasmada que venha a ser dirigida por uma metodologia desajustada corre o risco de se perder em meio aos dados e objetivos a qual se propõe o pesquisador. Entretanto, ao se enveredar pela pesquisa in loco nas prisões o pesquisador se depara com adversidades de naturezas diversas, as quais dividimos em quatro categorias principais que interagem e se influenciam em maiores ou menores intensidades: a burocracia, os aspectos éticos, relacionais (a maneira como o contato e o vínculo são estabelecidos com os atores da instituição) e técnicos (o modo como os dados são 
escolhidos para entrarem em pauta e como isto é feito empiricamente). Partindo deste conjunto de elementos, apresentaremos a seguir de modo não sequencial as particularidades de cada um destes segmentos em uma reflexão sobre o aspecto metodológico da pesquisa no sistema prisional a partir das duas perspectivas metodológicas sobre as quais se propõe essa reflexão.

\section{Portão da frente: desafios da pesquisa de fora para dentro da prisão}

Conforme mencionado, apesar de ser grande a produção acadêmica brasileira sobre instituições prisionais, sobretudo a partir dos anos 2000, são ainda poucos os trabalhos em que se propõe uma reflexão de natureza metodológica sobre a atividade de pesquisa nestes espaços fechados e de acesso restrito. Situar as possibilidades de acessar o conhecimento em locais de intensa vigilância e densos controles sociais - formais e informais - nos quais as condições de autonomia do pesquisador - nas decisões sobre a pesquisa, nos espaços por onde circula e sobre as pessoas com interage, bem como sobre as informações que recebe - são bastante restritas, constitui-se de peculiar importância metodológica e epistemológica.

Em geral, as reflexões desta natureza constituem trabalhos acadêmicos de mestrado e doutorado, especialmente, na condição de contexto da pesquisa ou de trajetória do pesquisador. Em geral, são reflexões mais descritivas que descortinam os desafios e os percalços das pesquisas, as mudanças de rumo e as escolhas feitas ou impostas ao pesquisador que, de certa, moldam os resultados da pesquisa que ali se apresenta (DIAS, 2008, 2013). Não se trata, portanto, de reflexões de natureza propriamente metodológica ou epistemológica já que o corpo principal do trabalho está voltado aos diversos temas que gravitam em torno do universo prisional (Lourenço; Alvarez, 2018).

Adorno (1991) e Dias $(2012,2015)$ propõem algumas questões acerca das condições de acesso às instituições fechadas (DIAS, 2015) e das relações que se estabelece entre pesquisador e presos (ADORNO, 1991; DIAS, 2012). Se posicionar num espaço em que o controle da circulação é rigoroso e no qual há a impossibilidade concreta de passar sem ser percebido ou sem perturbar o ambiente exigindo a mobilização de um número maior ou menor de funcionários para acompanhar o pesquisador, por exemplo - estão entre questões comumente abordados nestas reflexões.

As condições a partir das quais é possível estabelecer uma relação de confiança com os sujeitos que atuam nestas instituições - sejam eles funcionários ou presos - passa por uma série de mediações que envolvem variáveis, como gênero, classe, raça, idade, dentre outras, que figuram como elementos que podem aproximar ou distanciar, que podem repelir ou criar empatia e reconhecimento entre pesquisador e os sujeitos da pesquisa no âmbito da prisão (DIAS, 2015).

Além disso, o uso apropriado de técnicas de pesquisa mais ou menos adequadas para o contexto institucional - etnografia, questionário, entrevistas - e o local a partir do qual é permitido ao pesquisador acessar as dinâmicas internas da prisão, são sempre elementos importantes das reflexões metodológicas em tais instituições. O acesso ao conhecimento é sempre fragmentário, entrecortado por invisibilizações, silêncios e obscuridades. Em instituições fechadas essas características se impõem com maior nitidez sobre as condições da pesquisa e sobre o espaço possível de circulação do pesquisador, demarcando claramente limites espaciais e temporais, mas, também, limites profissionais e éticos (DIAS, 2013).

As restrições de acesso às instituições prisionais e as condições de pesquisa no interior destes estabelecimentos colocam barreiras claras no acesso ao conhecimento das dinâmicas carcerárias. Contudo, Wacquant (2012) aponta ainda que a própria organização profissional da vida acadêmica representa um empecilho para que pesquisadores possam realizar uma etnografia da vida prisional em uma longa duração, de forma a permitir a adaptação do pesquisador à vida atrás das grades e, 
desta forma, possibilitar uma apreensão do significado de práticas, representações e processos que ocorrem no interior de instituições fechadas. De acordo com o autor, seriam os comitês de ética de pesquisa acadêmica os primeiros obstáculos impostos para a pesquisa em profundidade nos estabelecimentos carcerários, alegando possíveis danos psicológicos ou físicos para os pesquisadores em tais situações. A compreensão desta dificuldade só se faz possível se situarmos novamente, de um lado, a prisão como campo (CHIES, 2015), marcada pela incerteza, por zonas de indistinção entre direito e não-direito; por outro lado, reposicionarmos o pesquisador como o sujeito que vem de fora e que, portanto, não se supõe submetido ao sentido da prisão como campo.

De fato, a realização de etnografias de longa duração em instituições prisionais apresenta obstáculos empíricos, teóricos, metodológicos e epistemológicos que vão muito além do preconizado por Wacquant. Em que pese, por exemplo, a disposição do pesquisador e a autorização da administração prisional para a permanência do sujeito na instituição por um tempo determinado, poderão emergir uma multiplicidade de outras questões que inviabilizem ou represente obstáculos de natureza diversa para a prática da imersão no campo. Questões relacionadas ao gênero (uma mulher poderia permanecer numa prisão masculina ou vice-versa?), à privacidade dos presos (eles seriam consultados sobre o novo 'hóspede'?), ao impacto da presença do pesquisador (ampliaria superlotação e o compartilhamento de produtos, serviços e espaços escassos), ao enquadramento normativo-legal (qual o lugar do pesquisador caso ele se deparasse com práticas ilícitas? E o que aconteceria se ele próprio se envolvesse em práticas desta natureza?) e éticas (impor-se voluntariamente e com uma finalidade utilitarista a condição de privação de liberdade por tempo que ele próprio define e acorda com as autoridades, diante dos outros indivíduos que estão nesta condição de forma coercitiva e em decorrência de uma punição que lhes foi imposta pelo Estado e que os coloca, neste sentido, em condição de ser observado pelo pesquisador que ali se encontra voluntariamente).

Além de tudo isso, considerando que o pesquisador se situa na posição acima destacada, em um universo caracterizado pela desconfiança, por controles formais e informais, por um sistema que funciona através de fugas das legalidades e de uma economia informal, qual seria a possibilidade concreta de o pesquisador conseguir acessar informações, conhecimentos e significados da vivência prisional quando ele vivencia tudo isso a partir de uma condição artificialmente criada? Qual a possibilidade concreta de estabelecer relações simétricas com os presos e com os funcionários? Considerando essa dupla relação que na prisão também assume um caráter de oposição simétrica, como se situaria o pesquisador diante de cada um desses atores na sua vivência carcerária?

Wacquant (2002) aponta a década de 1970 como sendo um período em que muitas pesquisas foram realizadas nas prisões dos Estados Unidos. Além disso, ele lembra que é também desta época que textos escritos por pessoas que estavam ou estiveram privadas de liberdade, se tornaram célebres - Malcom X (HALEY, 1965) e Angela Davis ([1974]2019) representam as grandes contribuições para o conhecimento das vida interna das prisões, através de narrativas reflexivas escritas por quem viveu a experiência de ser aprisionado. Além da descrição da experiência da vida na prisão, ambos se tornaram ícones políticos através das denúncias do racismo que estrutura o sistema prisional norteamericano, estabelecendo a relação da instituição prisional com a estrutura social, econômica e política mais abrangente e tornam-se porta-vozes da luta pelos direitos civis à população negra e, no caso, de Davis, especialmente das mulheres negras.

As dificuldades empíricas, metodológicas e epistemológicas de acessar a instituição prisional e, uma vez lá dentro, conseguir atravessar a opacidade das relações sociais e compreender o significado dos processos, das dinâmicas e das representações que ali se produzem, estão postas como questões centrais para a realização de qualquer pesquisa no sentido tradicional, isto é, de uma perspectiva externa. É certo que as estratégias utilizadas são capazes de acionar determinadas 
problemáticas e fazer emergir determinados problemas e complexidades, mas, são incapazes de dar respostas à todas as questões que desafiam a compreensão mais profunda deste universo social. Neste sentido, a proposta do texto de produzir uma reflexão metodológica que se produza a partir da dupla inserção do sujeito encarcerado-pesquisador, posição na qual a reflexão se constrói a partir do corpo e das experiências vividas na pele e na carne, aparece como uma proposta potente de aprofundar as reflexões que envolvem este campo de pesquisas, conforme apresentado a seguir.

\section{Caminho indesejado: quando a prisão faz emergir um pesquisador}

Conforme argumentamos anteriormente, existem diversos estudos sobre instituições prisionais que se efetuam a partir de uma perspectiva externa, onde o(a) pesquisador(a) adentra o território para então investigá-lo. Trataremos a seguir de uma perspectiva menos comum, onde o pesquisador é levado à instituição enquanto um membro da comunidade interna. Trata-se de uma literal imersão no ambiente prisional - ou seja, de um indivíduo que foi preso e que pretende fazer uso desta vivência interna para produzir um diálogo com estas perspectivas externas, expandindo seus limites investigativos ao interior das muralhas.

\section{Regras, atores e afetos: a Cartografia da prisão}

Visando uma contribuição metodológica para os estudos sociológicos das prisões e uma aproximação às inferências dos planos afetivos, o pesquisador-interno tem como proposta se respaldar na ferramenta da Cartografia, metodologia inspirada (porém não sistematizada) por Gilles Deleuze e Félix Guattari em sua obra Mil Platôs ([1980]2008). Desenvolvida por pesquisadores e pesquisadoras interessados em sistematizar uma ferramenta capaz de se valer dos fluxos de desejo e dos afetos no registro de processos em determinados territórios existenciais (PASSOS; KASTRUP; ESCÓSSIA, 2009; ROLNIK, 1989).

Para Deleuze, a partir de Spinoza ([1677]2009), afeto é “a variação contínua da força de existir na medida em que essa variação é determinada pelas ideias que se tem.” (1978, p.16), ou seja, o afeto são as intensidades que permitem ao corpo agir com maior ou menor potência, para esta ou aquela finalidade. Os afetos são as composições sentimentais do conjunto corpo-mente, suas ideias, seus deslocamentos. Para Deleuze e Guattari ([1980]2002), na esteira da noção de Biopolítica de Foucault (1979), na sociedade moderna os corpos são máquinas desejantes cujo investimento libidinal é recalcado e recodificado pela máquina capitalista para a produção e para o consumo irrefreado, bem como para a busca de satisfação nas relações de poder e de subjugação. $O$ corpo deixa de se desterritorializar e retorritorializar incessantemente, promovendo diferença e singularidade, para se fazer sujeição produtora de bens e serviços, codificado, territorializado, rígido, ausente de crítica, pautado em uma moral externa (DELEUZE; GUATTARI, [1980]2002)

Cartografar é utilizar-se dos agenciamentos afetivos do território para evidenciar justamente as possibilidades criativas, os devires, as transformações, as forças moleculares latentes que não se manifestaram e que silenciosamente pedem passagem. É manter-se atento às constantes investidas de máquinas de subjetivação e sobrecodificação do desejo que desviam sua capacidade produtiva para modos de existência que nada tem a ver com uma singularidade ética em si mesma, mas antes, com uma reprodução de modos alinhados com o exterior, com vistas à produção de riquezas materiais e impessoais (DELEUZE; GUATTARI, [1972]2010).

A experiência na prisão, os registros escritos, a memória do corpo, todos estes elementos coletados em campo são ingredientes que permitem uma aproximação do território prisional ao plano 
comum heterogêneo dos afetos, que vai além do aparato imediato da instituição e se relaciona também em nível molar com a sociedade em que se insere.

A Cartografia tem como premissa uma visão rizomática dos acontecimentos: nenhum gesto é isolado, nenhuma ideia tem origem própria e finalidade única - tudo é conectado, tudo se relaciona (DELEUZE; GUATTARI, [1980]2008). A violência no interior das grades é uma violência social, tão prejudicial quanto as violências de fora das grades, porém são violências distintas em seu grau de permissividade, em seus regimes de visibilidade e aceitação.

A Cartografia, devido a seu caráter de promover a amplitude e a multiplicidade de percursos, elenca em seu constante trajeto investigativo as inquietações e estratégias da Genealogia (LEMOS; CARDOSO JR., 2009), da (Auto)Etnografia (SANTOS, 2007), da Análise Institucional (PASSOS; ROSSI, 2014), da História Oral (GONÇALVES; LISBOA, 2007), da Música, das Artes, da Literatura etc.

O olhar cartográfico se propõe a transversalizar as intensidades em um esforço ético-estéticopolítico que permita trazer à tona questionamentos potencializadores de novas passagens, de novas possibilidades de existência. Neste sentido a Cartografia sempre será um método de pesquisaintervenção, visto que seu processo "requer do pesquisador uma indissociabilidade entre conhecimento e transformação, tanto da realidade quanto do pesquisador" (PASSOS; BENEVIDES, 2009).

Especificamente sobre a temática desta sessão do trabalho - a pesquisa em prisões com base em uma perspectiva interna - as pistas começam a surgir a partir do instante em que se observam as relações vivenciadas no interior da instituição, a partir das regras estabelecidas, dos afetos que são produzidos. O mapa começa a ser traçado, os atores passam a se apresentarem, a se tornarem acessíveis ao plano; a atenção do cartógrafo (KASTRUP, 2009) elege seus primeiros interlocutores e a investigação começa, enfim, a movimentar espaços emaranhados e a escutar vozes silenciadas.

Contudo, é preciso que novas investidas aconteçam constantemente no processo de pesquisa e que esta investigação seja criadora de ferramentas ainda desconhecidas - pois apenas o contato efetivo com as intensidades do Campo permitirão a identificação do caminho a ser percorrido.

Em sintonia com as aberturas possíveis aos caminhos e composições cartográficas, destacamse as propostas do método autoetnográfico, a saber, seu caráter altamente subjetivo e experimental. O período de tempo, a vivência e a memória do pesquisador no interior do Campo prisional convidao a realizar este exercício de aproximação entre Filosofia, Sociologia e Antropologia: sua pesquisa é sua história, suas impressões e sua relação com estes eventos, com estes grupos, com a sociedade e consigo mesmo.

A prática da autoetnografia consiste na "presença do corpo do(a) pesquisador(a) na linha de frente da pesquisa, no momento da criação (texto ou a performance/apresentação)" (BRILHANTE; MOREIRA, 2016, p.1100). A posição do(a) pesquisador(a) na linha de frente, traça os contornos epistemológicos do conhecimento produzido em consonância com o objetivo cartográfico de encontrar um plano comum de imanência da experiência afetiva do cárcere.

Tratam-se, portanto, de metodologias que exigem um alto grau de reflexividade, visto que procuram acompanhar um processo de experimentação que se atualiza no próprio corpo do(a) pesquisador(a).

Para darmos procedimento à discussão da perspectiva interna e elucidar as proposições metodológicas com maior clareza, serão apresentados elementos que compõem as esferas organizacionais e relacionais que consideramos relevantes na pesquisa da prisão: suas regras (internas e externas) e seus níveis de integração relacional (com a comunidade interna, com os agentes do Estado e com a comunidade externa). 


\section{Captura e normatização}

É implacável a metamorfose que um corpo sofre ao ser considerado delituoso. É como se houvesse uma chave invisível sobre cada um de nós que, quando acionada no momento da primeira abordagem, é imediatamente produzida a passagem de um corpo-cidadão a um corpo-bandido. Amparado nos interesses sócio históricos de excluir e docilizar grupos específicos de pessoas com o pretexto de reeducá-las (FOUCAULT, [1975] 2007), um corpo-bandido ao ser constituído passa a ter um limiar de controle infinitamente mais passível de intervenção por parte dos eleitos dispositivos sociais de segurança (polícia, agentes penitenciários, grades, muralhas, cadeados) do que um corpocidadão. É facilmente aceito e justificável o uso de força buscando a dominação de um corpo-bandido para que este responda por sua atividade considerada nociva à sociedade e se mantenha atrelado constantemente ao processo de penitência.

Ao ser então aprisionado, o corpo-bandido passa à custódia estatal e deve observar regras determinadas em um sentido amplo - o da Lei de Execução Penal - e em dois sentidos mais restritos - o das normas internas da instituição a qual faz parte e, concomitantemente, à que pode ser denominada Lei da Cadeia, uma espécie de código de conduta mais ou menos organizado que dita as regras do grupo de internos em seus convívios.

A Lei de Execução Penal serve para estabelecer, essencialmente no âmbito jurídico, os limites à ação do Estado enquanto agente de custódia de cidadãos infratores das leis. Via de regra, é uma lei de baixo impacto na realidade prisional no que diz respeito aos direitos dos presos, ao acesso a alimentação adequada, trabalho, lazer, proteção da dignidade e integridade física. Em complemento à legislação ampla e geral, os regimentos institucionais internos levam em consideração especificidades de cada prisão, procurando detalhar o funcionamento prisional de modo mais particular à realidade daquele território específico - sua regionalidade, seu grau de periculosidade, sua organização espacial, suas atividades laborais e educativas disponíveis, etc -. adequando assim tais peculiaridades à maior efetividade das normas e do processo de docilização destes corpos (FOUCAULT[1975]2007).

E, por fim, a Lei da Cadeia diz respeito a regras para um bom convívio dos internos. Criadas coletivamente pelo próprio grupo, sem um provável ponto de partida específico, a Lei da Cadeia diz respeito à maneira de se relacionar com os outros internos, ao espaço de cada um, aos pertences, aos familiares. Também diz respeito à reafirmação que o ambiente prisional se trata de um embate tenso quase constante entre presos e agentes penitenciários, como se tratassem de dois grupos rivais. É uma regra colaborar com quem está dentro, ao seu lado, e observar com desconfiança quem está fora. A Lei da Cadeia trata-se, além de um conjunto de regras de convívio, do estabelecimento de uma ética própria da população carcerária e se sobrepõe frequentemente a qualquer outra regra vinda de outras fontes de autoridade que não o coletivo estabelecido naquela comunidade (RAMALHO, [1976] 2002).

Sendo basicamente estes - Lei de Execução Penal, regimento institucional e Lei da Cadeia os códigos de legislação, normatização e conduta que incidem sobre os internos, a partir da vivência dentro do presídio é possível afirmar que todos se manifestam nestes corpos com intensidades diferentes, sendo ora rigorosas, ora flutuantes, ora inexistentes - e portanto é de interesse do pesquisador identificar estas alternâncias e suas (des)motivações.

Para exemplificar estas influências e sobreposições, tomemos a questão das drogas como parâmetro. Apesar da proibição e do gigantesco índice de presidiários encarcerados justamente pelo envolvimento com o tráfico de drogas, é extremamente comum e de conhecimento de todos o 
comércio e o consumo de drogas no interior dos presídios. Nas observações do interior da prisão foi constatado que o acesso é infinitamente mais fácil do que na sociedade civil aberta: basta se dirigir à pessoa certa, ou à cela certa, para se ter acesso à droga imediatamente - claro, mediante pagamento. Neste sentido, encontra-se a brecha regimental que leva o Estado a fazer a famosa "vista grossa" em relação ao consumo de drogas nas prisões e permite à Lei da Cadeia incorporar estes artefatos em suas diversas possibilidades de uso - Saúde (alimentação, sono ou recreação), controle subjetivo (dos portadores sobre os usuários) e comerciais (visto que se trata de uma mercadoria de grande valor devido à dificuldade de transpor as barreiras físicas das instituições).

Citemos brevemente ainda um outro exemplo, onde o conjunto de regras leva a uma recolocação dos internos em uma postura respeitosa não comum a todos: o dia de visitas. Devido à regra geral de tratar as visitas com o mais alto nível de respeito, existem nestas ocasiões momentos de comoção e de uma mudança brusca de comportamento, até mesmo nos internos mais exaltados. A presença dos familiares força cada um daquele espaço a se vestir, se apresentar e se comportar frente a estas visitas de uma maneira eventualmente pouco experimentada anteriormente por membros do grupo. A elevação no trato alheio reverbera positivamente, visto que traz a estes indivíduos momentos de paz coletiva - ainda que impositivamente pela Lei da Cadeia - que acabam por ressignificar a condição e a reputação de cada um frente ao grupo. O trato das visitas é, por assim dizer, uma afirmação da dignidade latente em cada interno.

Estes conjuntos de regras tem sentido e intensidade bastante diferentes das regras e leis gerais da sociedade livre. A limitação espacial, o constante estado de vigilância, a ausência de privacidade e o desejo por encontrar segurança e um mínimo de conforto em seu convívio tornam estas normativas muito mais palpáveis e indissociáveis nas condutas diárias em seus mínimos gestos.

Ao método, nos interessam estas normas, suas origens e fundamentações, no sentido em que são elas que forçam os processos subjetivos a tomarem novas formas, a penderem para este ou aquele padrão comportamental experimentados conforme nos exemplos citados rapidamente. Se nos interessa compreender tais produções, é necessário que se leve em consideração constantemente o peso e o caráter das leis e dos códigos de condutas impostos aos corpos aprisionados. Serão estas regras que basicamente irão permear as relações com os outros e consigo mesmo dentro do contexto prisional.

A seguir elencamos, portanto, os atores que transitam pelo espaço prisional e estabelecem relações entre si, tendo como parâmetro os tipos de códigos normativos elencados nesta sessão.

\section{Composição relacional interpessoal de um presídio}

A prisão é um universo físico deliberadamente limitado e limitante. Suas grades e muralhas servem como aparatos de controle inabaláveis frente à oposição dos corpos que sonham em romper com estes limites para viverem suas liberdades e satisfações do mundo de fora.

Importante ressaltar que o que se pretende pensar aqui não diz respeito, porém, a intensidades limitadas ao bojo da instituição prisional. Estas relações, suas imbricações, suas convergências, seus embates, todas estas produções extrapolam os limites físicos da instituição afetam o corpo social constantemente na mesma medida em que são produzidas, pois a prisão isola e cria um mundo dentro de outro mundo, ainda que haja no senso comum a ideia de que se tratem de coisas distintas facilitando a reprodução de discursos equivocados de que se prendermos os indivíduos corretos, tudo se resolve. Os movimentos de invisibilização da população carcerária esconde os atos e atores, mas não suprime seus efeitos. 
Ao propor uma perspectiva de integralidade dos mundos internos e externos, é possível considerar, a partir da vivência na prisão, uma representação das relações entre indivíduos que irão reverberar nestas composições, considerando os atores, suas vias de relacionamento e os espaços territoriais os quais ocupam.

No período encarcerado foi possível elencar os seguintes níveis relacionais interpessoais, de menor para maior intensidade de interações, a partir da vivência do pesquisador-interno:

- $\quad$ Os Internos da Cela;

- $\quad$ Os Internos do Pavilhão;

- Os Agentes Institucionais de Controle;

- $\quad$ Os Internos dos demais pavilhões;

- Os Agentes Institucionais de Assistência;

- $\quad$ Os visitantes Familiares;

- $\quad$ Os visitantes da Sociedade Civil;

- $\quad$ Os visitantes do Poder Judiciário.

Por Internos da Cela, compreendemos o nível mais direto e molecular de relações. É dentro das celas que as primeiras regras de convívio devem ser observadas. A limitação espacial é um fator de desconforto constante, e a higiene é muito prezada de modo geral, assim como o respeito pelos bens materiais de cada um (o ato de roubar de um outro Interno é falta gravíssima na Lei da Cadeia).

Por Internos do Pavilhão, nos referimos ao segundo nível relacional de um coletivo um pouco mais amplo, onde se incluem os internos que compartilham de um espaço de convivência e interação quando as portas das celas se abrem. Neste segundo nível as relações funcionais e recreativas tomam maior forma: as atividades físicas, os jogos, as trocas comerciais (vendas e escambos), as práticas religiosas, as amizades e, comumente, as conexões com novas formas de criminalidade. Esta categoria é possivelmente a mais ampla em suas variações, não sendo oportuno neste trabalho discorrer sobre cada uma delas, porém, muito brevemente, talvez seja possível considerar algumas categorias, tais quais: Internos Amistosos, Internos Agressivos, Internos Autodestrutivos, Internos Esquizofrênicos ou Dissociados, Internos Religiosos, Internos Forasteiros (de outros países e/ou culturas, como habitantes de estados longínquos e indígenas), Internos Pensadores, Internos Engenhosos, Internos Artistas, Internos Comerciantes... E mais uma enorme gama de categorias que podem se constituir nas personalidades dos Internos uma sobre as outras.

Por Agentes Institucionais de Controle tomamos os Agentes Penitenciários que vigiam e interagem com os Internos. São os responsáveis por manter a ordem quando os grupos de Internos do Pavilhão não resolvem suas desavenças a partir de suas próprias regras. São também estes os agentes que melhor personificam a política prisional do Estado, visto que são os responsáveis diretos pela tutela dos Internos. As relações entre os Agentes e os Internos são de um modo geral de desconfiança, porém, fugindo de generalizações, há os Agentes que conseguem produzir relações amistosas com os internos, chegando inclusive em determinados momentos a adentrarem o pavilhão sem ordenarem o recolhimento dos internos às celas.

Os Internos dos demais pavilhões são vistos e encontrados com frequência quando se tratam de trabalhadores. Na vivência do pesquisador-presidiário, observaram-se contatos com trabalhadores da padaria, da cantina, da barbearia, do Setor de Pertences (que entregam objetos e cartas que os internos recebem), da Biblioteca, das hortas, etc. Qualquer interação que vá além das realizadas no interior do próprio pavilhão é tida como um sinal de maior abertura à Instituição. Leva-se tempo para se conseguir, junto aos Agentes de Controle e de Assistência, a permissão para ampliar o espectro de 
ação dentro do território prisional (o autor-pesquisador-interno passou sete meses solicitando uma visita à Biblioteca antes de ser autorizado).

Os Agentes institucionais de Assistência compreendem aqueles agentes cujas funções centrais não dizem respeito a uma manutenção da ordem como os Agentes de Controle. Estes são Agentes responsáveis por prestarem suporte de outras ordens, se compondo assim de Assistentes Sociais, Psicólogas, Professoras, Médicos, Dentistas, Defensores Públicos, etc. Pelo que se foi estabelecido dentro da prisão, pode-se afirmar que estes Agentes apresentam um limiar de tolerância muito maior às demandas e desajustes dos internos que os Agentes de Controle.

Os Visitantes Familiares, sem dúvida, são a categoria que fornece maiores pontos de apoio da população prisional: o dia da visita "é sagrado". O clima de tensões tende a cessar nos dias de visitação, os internos em praticamente sua totalidade procuram usar roupas mais adequadas e manter um distanciamento das visitas alheias que inclui até mesmo o desvio do olhar. Outros internos só se aproximam dos seus familiares quando são convidados a fazê-lo, caso contrário se mantém quietos e discretos, interagindo com outros internos que não receberam visita. A Lei da Cadeia, na prisão onde o pesquisador foi encarcerado, dita que o mais antigo da cela tem a preferência de utilizá-la no dia de visita; as visitas dos demais integrantes da cela deveriam permanecer no pátio. São os familiares que levam objetos de uso cotidiano dos internos (roupas, jogos, rádios, televisões, baralhos, livros, dinheiro, cigarros etc), se mantendo, de modo geral, como elementos de conforto e fortalecimento subjetivo. Por se tratarem também da maior referência da vida pregressa à institucionalização, é possível afirmar que os Visitantes Familiares são aqueles que promovem ainda um efeito protetivo contra a dissociação e outras formas de sofrimento mental - elementos observados com grande ocorrência no contexto prisional, seja em surtos esporádicos, seja em indução a um quadro crônico de depressão, de mania, de persecutoriedade neurótica, de esquizofrenia, entre outros tantos desencadeados nos corpos aprisionados.

Os Visitantes da Sociedade Civil são, em sua maioria, representantes de organizações religiosas. Católicos, Espíritas, Evangélicos e Testemunhas de Jeová foram os visitantes mais frequentes desta categoria, e permaneciam dentro do pavilhão junto aos internos, propondo momentos de leitura, reflexão e conversa. Em seguida é possível citar os-as estudantes de Direito que realizavam visitas para conhecerem a Instituição e fazerem as articulações necessárias dentro de seus cursos. Essas visitas eram ocasiões raras onde, ao contrário de como ocorria com as visitas dos grupos religiosos, os Agentes de Controle nos ordenavam a entrar na cela, mesmo que estivéssemos no horário do banho de sol. Então, quando todos estávamos recolhidos, os/as estudantes adentravam o pavilhão sob nossos olhares curiosos. Muitos vinham até a boqueta (abertura na porta de ferro) para puxarem conversa, saciando algumas curiosidades. Éramos verdadeiros bichos em exposição nestes casos, mas não havia incômodo, pois estas visitas significavam as visões de rostos diferentes, trajando roupas de gente comum, e eventualmente também a presença de mulheres em um território preponderantemente masculino. Portanto esta categoria certamente diz respeito especialmente à quebra na rotina repetitiva e cansativa do grupo de internos que as recebem.

Por fim, consideramos a última categoria, os Visitantes do Poder Judiciário. Eram visitas raras e rápidas. Geralmente um Juíz realiza esse tipo de visitação escoltado por diversos guardas fortemente armados. Se dirigem até a grade do pavilhão acompanhados de agentes administrativos do presídio. Fazem comentários, conversam entre si e, algumas vezes, puxam conversa com os internos curiosos do outro lado da grade. Trata-se certamente de uma inspeção das conduções e condições da instituição.

Tendo apresentado cada categoria brevemente, é importante ressaltar que se considera difícil precisar esta composição como universal de todas as prisões, mas é possível considerá-la abrangente 
o suficiente para se propor como ponto de partida para uma investigação que se proponha considerar as possíveis relações entre indivíduos na instituição, de dentro para fora.

É também essencial pontuar uma relação não elencada por se tratar de uma outra ordem relacional, de caráter meramente especulativo, abstrato e indireto. Trata-se da relação do interno com sua reputação no mundo externo, ou seja, com a ideia que alimenta acerca do juízo que fazem ou virão a fazer futuramente a seu respeito seus conhecidos próximos (familiares que não o podem visitar, amigos, pessoas próximas de sua comunidade) e desconhecidos (possíveis empregadores, possíveis relacionamentos amorosos, etc) sobre o fato de estar impedido de exercer sua liberdade. O medo do estigma, da taxação, do rebaixamento, ou a esperança de reconhecimento e honra: este é um meio indireto de se relacionar com o corpo social que causa (ao menos em parte da população carcerária) afetos de medo e vergonha, ou, em casos de indivíduos com pretensões de maiores feitos no mundo do crime, de orgulho e fortalecimento moral. Ainda que seja de ordem distinta das demais relações apresentadas, estas intensidades são em determinados momentos tão vívidas quanto as experimentadas nas relações com pessoas presentes fisicamente.

Tendo explanado brevemente sobre as normas institucionais e das relações possíveis dentro do presídio observadas a partir de uma visão interna autoetnográfica, passamos agora a considerar as eventuais barreiras investigativas dentro destas premissas.

\section{O Registro e a Fuga da realidade: desafios de pesquisar por dentro}

Fazer registros em um regime de controle rigoroso de uma instituição prisional foi algo realmente desafiador. Havia sempre o medo que o que estava sendo escrito pudesse cair em mãos de outras pessoas e que a interpretação dada pudesse causar maiores prejuízos em seu convívio e em sua própria integridade física.

Apesar do receio, foi se desenvolvendo a escrita sobre o dia a dia durante muitos meses, em cadernos escolares do tipo brochura que eram vendidos na cantina do presídio - seus diários de campo improvisados. A atenção na escrita era dirigida essencialmente em dois sentidos: primeiro o de captar os comportamentos que mais lhe causavam curiosidade ou estranheza, o que lhe auxiliava tanto nos propósitos da pesquisa quanto no processo de elaboração da realidade vivenciada; e segundo, escrevia para se apoiar naquilo que lhe servia no mundo de fora - recordava pessoas, datas, descrevia acontecimentos felizes e tristes.

Interessante pontuar aqui uma diferença relevante em relação a posição externa de pesquisa. Neste contexto, ao término do encontro as anotações são levadas em segurança pelo pesquisador visitante para o outro lado das grades.

Já na vivência interna, os cadernos, como todo o restante dos materiais de pesquisa, ficam nas celas, com fácil acesso de um grande número de internos e, eventualmente, de Agentes Penitenciários.

Havia, portanto, especialmente nos primeiros meses, o receio de que encontrassem registros de passagens violentas, ou de outros delitos que aconteciam no pavilhão - tráfico de drogas, fabricação de choca (fermentado alcoólico de pão e cascas de frutas), conversas sobre crimes futuros, planos de vinganças etc., o que poderia ocasionar sérios prejuízos ao pesquisador-presidiário.

Não demorou para que se percebesse que mexer em pertences de outras pessoas é uma grande falha aos olhos da lei da cadeia, então seria muito difícil que alguém se arriscasse por meia dúzia de cadernos. Também o fato de ter conquistado o respeito do pavilhão trouxe uma blindagem ainda maior contra esse tipo de investida. De qualquer maneira, considerou-se prudente manter uma escrita não muito clara em determinados trechos, por vezes fazendo uso de abreviações e até mesmo de palavras em outras línguas. 
Apesar dos riscos envolvidos, ao final dos 11 meses em que esteve na condição de internopesquisador, foi possível reunir não apenas uma coleção de escritos próprios, mas também de outros internos que lhe confiaram suas palavras. Tão fundamental quanto as palavras em si a respeito do cotidiano e dos atores ali presentes, foi o registro em memória - agora reavivada quando em contato com o arquivo reunido. A leitura de cada trecho permite ao corpo-pesquisador recobrar sensações de quando fora corpo-presidiário, tornar manifestas as impressões latentes que aguardam seus momentos de ressurgimento em forma de correlações investigativas.

Importante ressaltar aqui que, além dos períodos sóbrios e vívidos carentes de maior observância da ética na exposição dos fatos, por outro lado em determinados períodos muito pouco foi registrado no material escrito, e o que ali se encontra tem pouco ou nenhum nexo. Estes hiatos de renúncia literal ocorreram no período de maior desesperança ali dentro. Após meses de prisão, mais especificamente, após o oitavo mês no cárcere, alguns questionamentos mais severos em relação à própria realidade começaram a acontecer. O presidiário-pesquisador dirigia-se ao pátio olhando para as pessoas ao redor sem saber se elas estavam mesmo ali, ou se eram obras de sua imaginação.

Ou seja, também é a própria vivência e as experiências marcadas no corpo do presidiáriopesquisador que estabelecem limites para o conhecimento produzido a partir dessa posição. $\mathrm{O}$ constante estado de exceção e incerteza sobre a subjetividade colocam os indivíduos em uma pressão que em um momento, cedo ou tarde, irá colocar em xeque o que há de concreto e acessível aos sentidos em nome de alteridades mais brandas. De fato, os reflexos na saúde mental dos corpos aprisionados são notáveis, sendo comum a ocorrência de crises esporádicas, bem como o surgimento de quadros crônicos de transtornos mentais (CONSTANTINO, ASSIS \& PINTO, 2016).

É certo, portanto considerar que quando é o próprio corpo que está inserido no processo de aprisionamento, existem limitações de outra ordem. É constante o desafio de se autopreservar e poder, dessa forma, compor memórias inteligíveis. Considera-se, portanto, no processo já iniciado de pesquisa no parâmetro interno, encontrar uma possível saída para este impasse no contato com os registros escritos e no estabelecimento de uma ordem cronológica dos acontecimentos que permita, se não uma reavivação, uma aproximação honesta do estado do corpo naqueles instantes de ausência de sentido, bem como tangenciar o ininteligível para que se faça inteligível dentro do cenário maior.

Independentemente de sua substância mais ou menos concreta - material ou em memória toda a leitura destas passagens deve ser permeada por uma atenção especial em relação à ética do que foi compartilhado pelos companheiros de convívio, com especial atenção justamente àquilo que emerge em caráter transversal na subjetividade dos corpos aprisionados, àquilo que escapa das investidas normatizadoras e se manifesta como força de criação, como potencialidade da expressão de si (GUATTARI; ROLNIK, 1986). Tão essencial quanto as denúncias das violências e mazelas do campo da prisão, se faz necessário desvendar as produções destes corpos que se desvencilham dos efeitos do castigo para produzirem afetos e encontros autênticos e harmônicos nas relações com o mundo.

\section{Considerações Finais}

Conforme afirmamos antes, no Brasil não são numerosos os trabalhos que se propõem a refletir metodologicamente sobre a pesquisa em instituições prisionais. São ainda mais raros, para não dizer inexistentes, trabalhos cujas análises partem de uma estratégica metodológica inovadora em suas práticas e reflexões epistemológicas como a que se produz quando o lugar ocupado pelo sujeito encarcerado é o ponto no qual se ancora a percepção das paisagens subjetivas e psicossociais realizada por meio de um exercício de reflexão autoetnográfico. Situar as condições de construção do 
conhecimento sobre o espaço prisional tomando como ponto de partida a perspectiva externa, tradicional no campo das ciências sociais, mas, alcançando a dimensão possível com a prática da autoetnografia do sujeito encarcerado e da produção de uma cartografia dos processos subjetivos em movimento no território do cárcere pode nos permitir avançar na discussão epistemológica sobre o conhecimento do universo prisional e contribuir com o campo dos estudos prisionais e com o campo de reflexões metodológicas no âmbito das ciências sociais.

Com base nas reflexões metodológicas propostas neste texto, consideramos ter contribuído para a reflexão por meio da construção de aberturas cruzadas entre as visões interna e externa da pesquisa em prisões. A observação desses modos de se relacionar evidenciou dificuldades e potencialidades, mas, para além de qualquer objetividade pretensiosa de bramir conclusões definitivas, serviu para colocar em pauta interlocuções práticas e teóricas multidisciplinares pouco exploradas.

O trabalho realizado "a quatro mãos", conforme nomeamos, permitiu intensos momentos de identificação e estranhamento típicos do trabalho de campo em ciências humanas. Nós pesquisamos a nós mesmos, a nossas maneiras de olharmos para o campo e para nosso leque de ferramentas investigativas, e percebemos que, por mais que pudéssemos nos dedicar à troca e à composição, jamais estaríamos sequer próximos de esgotar as possibilidades. As instituições prisionais são gigantes que arrastam em si um emaranhado de complicadores extremamente cristalizados, originados em práticas persistentes na sociedade, e propor investidas de fora para dentro e de dentro para fora das muralhas é um exercício que dificilmente caberia em um trabalho breve e, até então, inteiramente baseado em experimentações já vividas. O método, assim como a pesquisa, é vivo, ativo, metamorfo, e deve se mover com a mesma velocidade que as forças contrárias, estas forças reacionárias que procuram manter a ordem instituída como sendo a única possível - mesmo que se trate, no caso das prisões, de impor nos corpos aprisionados sanções físicas e psicológicas que boicotam sistematicamente as possibilidades da vida social em harmonia, ainda em pleno século XXI.

O caráter multidisciplinar apresentado - a saber, inspirado em fontes da Sociologia, da Antropologia, da Geografia, da Psicologia e da Filosofia - nos parece ilustrar em si mesmo o esforço e o interesse pela consistência adequada no embate com os imponentes gigantes de concreto e aço nos campos práticos e teóricos. Neste contexto rígido e controlado, a busca pelos afetos é a busca pelas engrenagens e pelas ferrugens desta composição.

Não há dúvidas que o que foi aqui apresentado deverá ser explorado com maior atenção em trabalhos posteriores, e que neste percurso novas possibilidades ainda veladas virão a se apresentar, porém do mesmo modo acreditamos que as possibilidades já criadas e explicitadas aqui brevemente poderão servir de pavimento para consideráveis avanços no campo da pesquisa em prisões. 


\section{Bibliografia}

ADORNO, S. Gestão urbana do medo e da insegurança: violência, crime e justiça penal na sociedade contemporânea. São Paulo, tese de livre-docência, FFLCH-USP, 1996.

ADORNO, S. Sistema penitenciário no Brasil. Revista USP, São Paulo, n. 9-1, 1991, p. 65-78.

ADORNO, S. A prisão sob a ótica de seus protagonistas: Itinerário de uma pesquisa. Tempo Social, São Paulo, v. 3, n. 1-2, 1991a, p. 7-40.

ADORNO, S.; BORDINI. E. Socialização na delinquência: Reincidentes penitenciários em São Paulo. Cadernos Ceru, São Paulo, série 2, n. 3, 1991, p. 113-47.

ADORNO, S.; DIAS, C. Fronteiras em mutação: um novo paradigma na sociologia das prisões?. In: Del Priore, M.; Müller, A. (Orgs.). História dos crimes e da violência no Brasil. $1^{\mathrm{a}}$ ed. São Paulo: Editora UNESP, p. 433-459, 2017.

ADORNO, S.; SALLA, F. Criminalidade organizada nas prisões e os ataques do PCC. Estudos Avançados, São Paulo, v. 21, n. 61, set./out. 2007, p. 7-29.

ANISTIA INTERNACIONAL. Informe 2020/21 - O Estado dos Direitos Humanos no Mundo. Disponível em <https://anistia.org.br/informe-anual/informe-anual-2020-o-estado-dos-direitos-humanos-nomundo/>. Acesso em: 29 maio 2021.

BRASIL. Ministério da Justiça. Levantamento Nacional de Informações Penitenciárias Infopen. 2019.

BRASIL. Lei no 7.210, de 11 de julho de 1984. Lei de Execução Penal. Disponível em: . Acesso em: 30 dez. 2020.

BRILHANTE, A. M.; MOREIRA, C. Formas, fôrmas e fragmentos: uma exploração performática e autoetnográfica das lacunas, quebras e rachaduras na produção de conhecimento acadêmico. Interface (Botucatu), v. 20, p. 1099-1113, 2016.

BRITO, J. S. Relações de poder e representações acerca do trabalho da mulher presa. Dissertação (mestrado) - Curso de Ciências Humanas e Sociais, Universidade Federal do ABC, 2017.

CASTRO, M. P.. Ciranda do medo: Controle e dominação no cotidiano da prisão. Revista USP, n. 9-1, p. 57-64, 1991.

CLEMMER, Donald. The prison community. Nova York: Rinehart \& Company, 1958.

COELHO, E. C. Ofi cina do Diabo e Outros Escritos Prisionais. Rio de Janeiro: Record, 2005.

CONSTANTINO, P; ASSIS, S. G.; PINTO, L. We. O impacto da prisão na saúde mental dos presos do estado do Rio de Janeiro. Ciência \& saúde coletiva, Rio de Janeiro, v. 21, n. 7, p. 2089-2100, 2016.

DAVIS, Angela. Uma autobiografia. Trad. de Hecci Regina Candiani. São Paulo: Boitempo, 2019.

DELEUZE, G.; GUATTARI, F. Mil Platôs: capitalismo e esquizofrenia, vol. 4. São Paulo: Ed. 34, $[1980] 2008$.

DELEUZE, G.; GUATTARI, F. O anti-Édipo: capitalismo e esquizofrenia. São Paulo: Editora 34, [1972]2010.

DIAS, C. N.. "Por dentro (e de dentro) do Comando: O PCC segundo o 'nativo'. Resenha de Junto e 
Misturado: uma etnografia do PCC, de Karina Biondi”. Dilemas: Revista de Estudos de Conflito e Controle Social, Rio de Janeiro, n.8, v.3, abr-jun, p. 159-172, 2010.

DIAS, C. N. A igreja como refúgio e a Bíblia como esconderijo: religião e violência na prisão. São Paulo: Humanitas, 2008a.

DIAS, C. N. A sujeição pela disciplina: Religião e castigo na prisão. Revista Brasileira de Ciências Criminais, São Paulo, ano 16, n. 73, jul.-ago, p. 268-98, 2008 b.

DIAS, C. N. Estado e PCC tecendo as tramas do poder arbitrário nas prisões. Tempo Social (USP. Impresso), v. 23, p. 213-233, 2011.

DIAS, C. N.; SILVESTRE, G. Situação carcerária no estado de São Paulo. In: SOUZA, Luís Antônio Francisco de (Org). Políticas de segurança pública no estado de São Paulo. São Paulo: Cultura Acadêmica/Editora Unesp, p. 91-105, 2009.

DIAS, C. N.; SALLA, F. Formal and informal controls and punishment: the production of order in the prisons of Sao Paulo. Prison Service Journal, v.229, p.19-22, 2017.

ESPINOZA, B. Ética. Belo Horizonte: Autêntica Editora, [1677]2009.

FOUCAULT, M. Vigiar e punir: nascimento da prisão. Petrópolis: Vozes, [1975]2007.

FOUCAULT, M. Microfísica do poder. Rio de Janeiro: Graal, 1979.

GODOI, Rafael. Ao redor e através da prisão: Cartografias do dispositivo carcerário contemporâneo. Dissertação de Mestrado em Sociologia. Faculdade de Filosofia, Letras e Ciências Humanas da Universidade de São Paulo, 2010.

GODOI, Rafael. A prisão fora e acima da lei. Tempo Social, São Paulo, v. 31, n. 3, p. 141-160, Dec. 2019.

GOFFMAN, E. Manicômios, prisões e conventos. São Paulo: Perspectiva, 1987.

GONÇALVES, R.C., LISBOA, T.K. Sobre o método da história oral em sua modalidade trajetórias de vida. Katálysis, vol.10, Florianópolis, 2007

GUATTARI, F.; ROLNIK, S. Micropolitica: cartografias do desejo. Rio de Janeiro: Vozes, 1986.

HALLEY, A. Autobiografia de Malcolm X. Trad. de A. B. Pinheiro de Lemos. Rio de Janeiro: Record, 1965.

HRW - HUMAN RIGHTS WATCH. Brazil Watch Report (2020). Disponível em $<$ https://www.hrw.org/pt/world-report/2020/country-chapters/336671>. Acesso em: 29 mai. 2021.

KASTRUP, V. O funcionamento da atenção no trabalho do cartógrafo. In: PASSOS, E.; KASTRUP, V.; ESCÓSSIA, L. da (Org.). Pistas do método da cartografia: pesquisa-intervenção e produção de subjetividade. Porto Alegre: Sulina, p.15, 2009.

LEMOS, F. C. S; CARDOSO JR., H. R. A Genealogia em Foucault: uma trajetória. Revista Psicologia \& Sociedade, vol. 21, 2009, p. 353-357.

MARQUES, G. da S.; GIONGO, C.R.; RUCKERT, C. Saúde mental de agentes penitenciários no Brasil: uma revisão sistemática da literatura. DIÁLOGO, Canoas, n. 38, p. 89-98, ago. 2018.

MISSE, M. Crime, sujeito e sujeição criminal: aspectos de uma contribuição analítica sobre a categoria “bandido”. São Paulo: Revista Lua Nova, 2010. 
MISSE, M. Crime e violência no Brasil contemporâneo: estudos de sociologia do crime e da violência urbana. Rio de Janeiro, Lúmen Júris, 2006.

NEV - Núcleo de Estudos da Violência. Relatório de Direitos Humanos (2020) - A Incompletude da Democracia no Brasil e o Retrocesso dos Direitos Humanos. Disponível em: $<$ https://nev.prp.usp.br/wp-content/uploads/2021/02/texto_rdh_psp.pdf>. Acesso em: 29 mai. 2021.

PASSOS, E.; BENEVIDES DE BARROS, R. A cartografia como método de pesquisa-intervenção. In: PASSOS, E.; KASTRUP, V.; ESCÓSSIA, L. (Orgs.). Pistas do método da cartografia: pesquisa intervenção e produção de subjetividade. Porto Alegre: Sulina, p. 17-31, 2009.

PASSOS, E.; KASTRUP, V.; ESCÓSSIA, L. da (Orgs.). Pistas do método da cartografia: pesquisaintervenção e produção de subjetividade. Porto Alegre: Sulina, 2009.

RAMALHO, José Ricardo. O mundo do crime: A ordem pelo avesso. São Paulo, Ibccrim, [1976] 2002.

ROLNIK, S. Cartografia sentimental: transformações contemporâneas do desejo. São Paulo: Estação Liberdade, 1989.

SANTOS, S. M. A. O método da autoetnografia na pesquisa sociológica: atores, perspectivas e desafios. Plural, v.24, p.214-241, 2017.

SINHORETTO, Jacqueline. Mapa do encarceramento: os jovens do Brasil. Secretaria Nacional da Juventude/Secretaria Geral da Presidência da República, 2015.

SYKES, Gresham M. The society of captives: A study of a maximum security prison. Princeton: Princeton University Press, 1974.

THOMPSON, Augusto. A questão penitenciária. Rio de Janeiro: Forense, [1976] 2002. 